\title{
SÍNDROME DA ARTÉRIA MESENTÉRICA SUPERIOR
}

\author{
SUPERIOR MESENTERIC ARTERY SYNDROME
}

\author{
Haberlandh Sodré Lima, TCBC-RJ ${ }^{1}$ \\ Accyoli Moreira Maia, TCBC-RJ ${ }^{2}$ \\ Antonio Kneipp Pitta de Castro Neto 3 .
}

\section{INTRODUÇÃO}

A Síndrome da Artéria Mesentérica Superior (SAMS), é uma entidade rara causada por compressão da terceira porção do duodeno pela artéria mesentérica superior e a aorta abdominal, resultando em obstrução aguda ou crônica deste segmento. Por vezes o diagnóstico de certeza torna-se difícil pelos sintomas semelhantes com várias moléstias do trato digestivo.

Este artigo relata um caso desta afecção, em uma paciente cronicamente doente .

\section{RELATO DO CASO}

AVB, 83 anos, sexo feminino, foi internada em 05/ 01/99, com quadro clínico de febre e vômitos biliosos com restos alimentares. Na história patológica pregressa, verificou-se que há mais ou menos seis anos encontrava-se restrita ao leito devido a doença de Alzheimer. Ao exame apresentava emagrecimento acentuado, hipo-hidratada com mucosas hipocoradas e anictéricas. Aparelhos cardiovascular e pulmonar sem alterações dignas de nota na ocasião. Abdomen plano com discreta distensão epigástrica e à ausculta os ruídos peristálticos estavam normais. Durante a internação, evoluiu com parada de eliminação de gases e fezes e piora dos vômitos .

A rotina radiológica para abdomen agudo mostrou importante distensão gástrica. Após a colocação de sonda nasogástrica (SNG), coletou-se aproximadamente $3000 \mathrm{ml}$ de secreção líquida de estase com restos

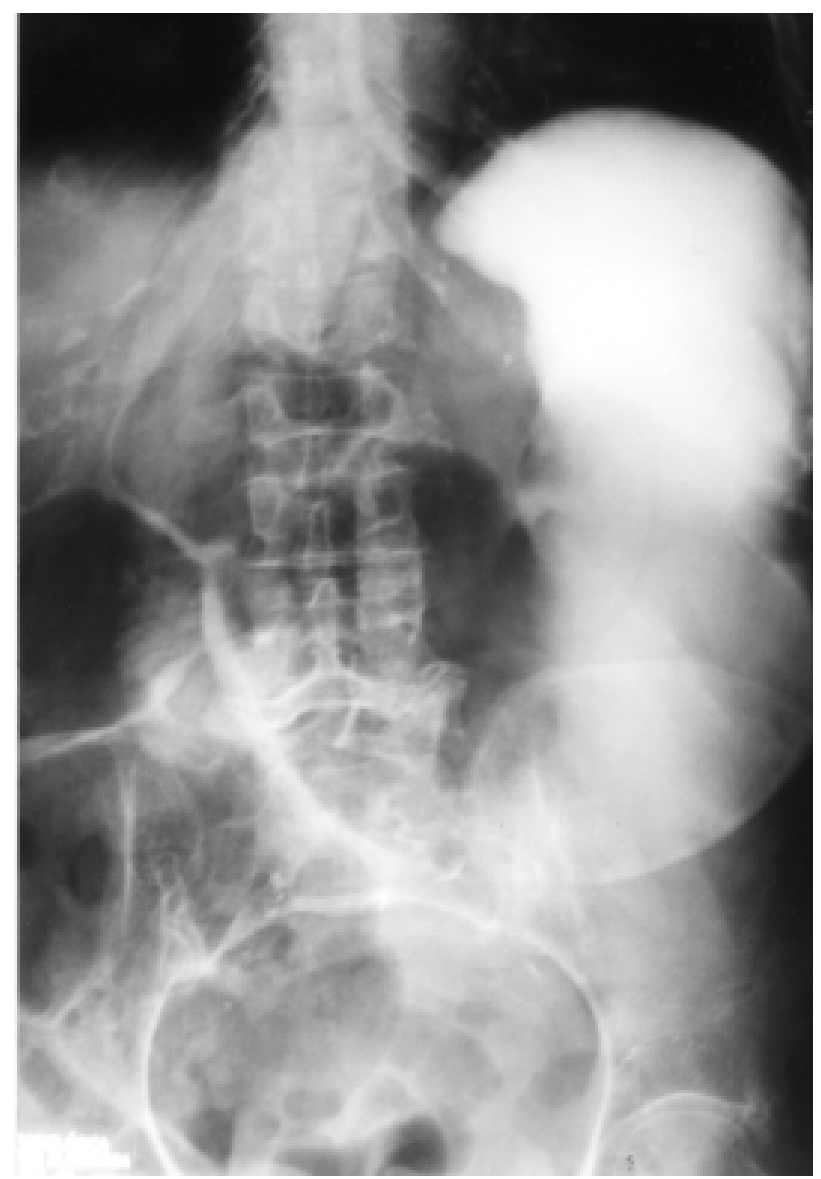

Figura 1 - Estudo contrastado. Dilatação gástrica com retenção de contraste.

1. Professor Adjunto do Departamento de Cirurgia Geral da Universidade Federal Fluminense.

2. Professor Titular do Departamento de Cirurgia Geral da Universidade Federal Fluminense.

3. Residente do Departamento de Cirurgia Geral da Universidade Federal Fluminense.

Recebido em 12/5/99

Aceito para publicação em 10/12/99

Trabalho realizado no Serviço de Cirurgia Geral da Casa de Saúde Alcantara, São Gonçalo-RJ. 


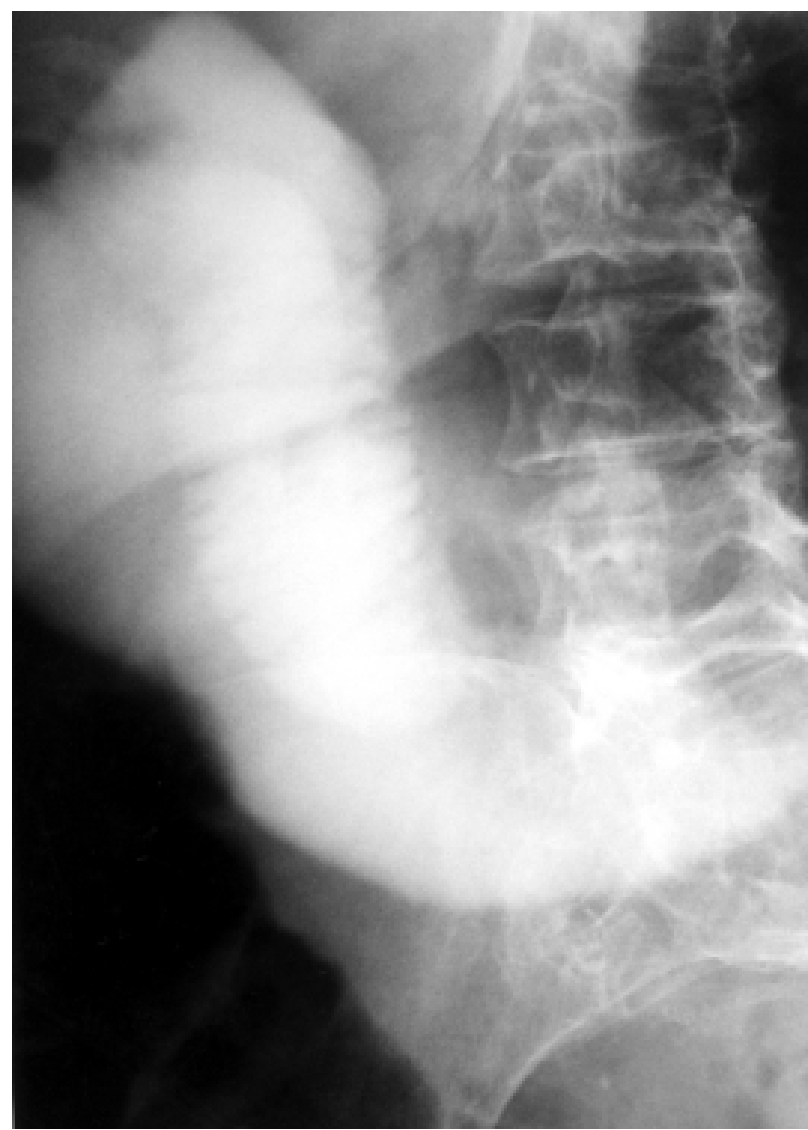

Figura 2 - Estudo contrastado. Dilatação duodenal com retenção de contraste na terceira porção.

alimentares. A endoscopia digestiva alta mostrou retenção do conteúdo gástrico e dilatação da primeira e segunda porções do duodeno. O exame radiológico contrastado do trato digestivo superior revelou estômago aumentado de volume, hipotônico, com dificuldade de esvaziamento (Figura 1) e dilatação da primeira e segunda porções do duodeno com parada do contraste ao nível da terceira porção (Figura 2), sugerindo compressão extrínseca de natureza vascular, compatível com a SAMS , uma vez que se desfazia quando adotado o decúbito lateral esquerdo.

Foi instituído inicialmente o tratamento clínico com dieta líquida e pastosa associado a mudança de decúbito , sem sucesso. Optou-se então pelo tratamento cirúrgico e executou-se uma duodeno-jejunostomia láterolateral retrocólica . Apesar da resolução do quadro obstrutivo após a intervenção cirúrgica , a paciente apresentou complicações cardiovasculares e evoluiu para o óbito no vigésimo dia pós-operatório .

\section{DISCUSSÃO}

A SAMS foi descrita por von Rokitansky em 1861 e desde então tem sido motivo de controvérsia entre vários autores, pois alguns não aceitam a compressão vascular como causa de obstrução duodenal. ${ }^{1,2}$

A gordura retroperitoneal tende a manter a raiz do mesentério e a artéria mesentérica superior afastadas da aorta. $\mathrm{O}$ ângulo entre as duas artérias situa-se em torno de 25 a 60 graus em indivíduos normais enquanto nos portadores da síndrome varia de 6 a 15 graus. ${ }^{1,3}$

Vários fatores podem levar à diminuição deste espaço entre estas duas estruturas vasculares, dentre as quais podemos citar: trauma crânio encefálico grave, permanência prolongada em decúbito dorsal no leito, imobilização em aparelho de hiperextensão, perda ponderal acentuada por doenças consumptivas, desordens dietéticas etc. ${ }^{3}$

Deve-se alertar que, inicialmente, os pacientes queixam-se de plenitude pós-prandial, anorexia e malestar epigástrico, e a seguir, apresentam náuseas e vômitos biliosos. Esta condição de impossibilidade de ingesta alimentar parcial ou total, conduz ao agravamento do quadro clínico, contribuindo sobretudo para uma maior perda ponderal e estabelecendo um quadro vicioso que traz conseqüências por vezes desastrosas para os pacientes .

O diagnóstico de certeza no pré-operatório é difícil, porém, uma vez suspeitado, a utilização de um estudo contrastado do duodeno pode fornecer uma série de sinais compatíveis com a SAMS., ${ }^{1,2,4}$

1. Dilatação da primeira e segunda porções duodenais com ou sem ectasia gástrica.

2. Compressão do arco duodenal com dificuldade e/ou parada de trânsito do meio de contraste.

3. Estase do meio de contraste no nível gastrintestinal por mais de quatro horas.

4. Desaparecimento da obstrução com mudança para decúbito lateral esquerdo ou ventral.

A duodenografia hipotônica também pode ser utilizada conforme relato de alguns autores nacionais. ${ }^{5}$

Inicialmente a abordagem clínica está indicada em todos os casos, através da introdução de uma sonda nasogástrica para descompressão do estômago, associada à correção dos distúrbios do equilíbrio hídrico-eletrolítico e ácido-base, por via venosa e, quando possível, a restituição da alimentação oral com pequenos volumes em intervalos curtos e mudança de decúbito. Em casos mais graves pode haver necessidade de nutrição parenteral total.

O tratamento cirúrgico, quando indicado, consiste, na maioria das vezes, na execução de uma duodenojejunostomia, porém, outros procedimentos podem ser utilizados tais como: a gastrojejunostomia e a operação de Strong ${ }^{3,5}$ (secção do ligamento de Treitz).

A nossa paciente foi tratada com duodenojejunostomia látero-lateral com sutura em plano único em posição retrocólica.

Como consideração final, chamamos a atenção que a suspeição desta síndrome deve ser lembrada sempre que pacientes emagrecidos apresentem um quadro sugestivo de obstrução alta. 


\begin{abstract}
The Superior Mesenteric Syndrome is a rare and controversial disease. The compression of the duodenum by the mesenteric artery and aorta causes an intermitent obstruction. Preoperative diagnosis is very difficult. We present one case of this syndrome in a pacient with severe weight loss and signs of high intestinal obstruction. The diagnosis was based on clinical and radiologic findings. A duodenojejunostomy was performed after medical treatment failure.This patient died on the $20^{\text {th }}$ posoperative day due to cardiac complications. This syndrome must be remembered in cases of high obstruction in chronic ill patients.
\end{abstract}

Key Words: Duodenal obstruction; Mesenteric artery syndrome.

\section{REFERÊNCIAS}

1. Cohen LB, et al. - The Superior mesenteric artery syndrome. J Clin Gastr 1985; 7: 113-116.

2. Gustafsson L, Falk A, Lukes PJ et al. - Diagnosis and treatment of superior mesenteric artery syndrome. Br J Surg 1984; 71: 499-501.

3. Eaton SB; Ferrucci JT - Radiology of the pancreas and duodenum. Philadelphia, London, Toronto: WB Saunders Company, 1973. p. 218-325

4. Burgener FA, Kormano M - Differential diagnosis in conventional radiology. Stuttgart; New York: Thieme; New York Thieme-Stritor, 1985.
5. Alvarez GC, Dalbosco MH et al. - Síndrome da artéria mesentérica superior. Rev Col Bras Cir 1994; 21: 225-226.

\section{ENDEREÇO PARA CORRESPONDÊNCIA}

Dr. Haberlandh Sodré Lima

Rua Pedro de Carvalho, 447/302

20725-230 - Rio de Janeiro-RJ 